\title{
Organizational and Tactical Measures to Identify and Document Crimes in the Field of Illegal Coal Mining
}

\author{
Yury Volgin ${ }^{1, *}$, Valery Togulev ${ }^{1}$, and Tamara Chernenko ${ }^{1}$ \\ ${ }^{1}$ Kemerovo State University, 650000, 6 Krasnaya st., Kemerovo, Russia
}

\begin{abstract}
In the article, the identification and documentation of crimes in the field of illegal coal mining as two interrelated processes are considered. Based on the consideration of the nature of crimes detection, directions and objects of documentation, the following proposals are formulated: on the formation of sources of operational search information; on the list of search features; on the list of operational investigative measures that are appropriate to carry out for solving the problem of bringing perpetrators to criminal responsibility. The list of open sources from which the primary information about the facts of being prepared, committed or having been committed crimes in the field of illegal coal mining is considered. A list of persons who may be involved in confidential assistance in order to obtain covert operational search information is also proposed. In order to ensure effective activity in detecting the facts of preparation and commission of crimes in the field of illegal coal mining, a list of search characteristics is proposed that can indicate facts of illegal activity. Suggestions regarding operational search measures have also been formulated, which allow the effective and timely detection, suppression and solving the crimes in the field of illegal coal mining.
\end{abstract}

\section{Introduction}

Among the measures implemented by the operational units of economic security and anticorruption of the internal affairs bodies to combat illegal coal mining, a special role is given to such forms of operational-search activities as identification and documentation.

The identification and documentation of crimes in the field of illegal coal mining are two interrelated processes. The effectiveness of the implementation of these forms depends on a number of factors. These, in our opinion, should include the following: the availability of reliable sources of operational investigative information, including secretive sources; knowledge by persons providing confidential assistance of signs indicating possible facts of criminal activity; a list of operational investigative measures, the implementation of which allows solving effectively the problem of combating illegal coal mining.

These circumstances make it necessary to consider the organizational and tactical foundations for identifying and documenting crimes in the field of illegal coal mining.

*Corresponding author: volgin384@mail.ru 


\section{Materials and Methods}

Identification of crimes in the field of illegal coal mining, as well as other economic crimes [1], represents the activities of the operational units of economic security and anticorruption, including:

- search and receipt of primary operational search data (primary information) about signs of crimes in the field of illegal coal mining;

- verification of primary information about crimes in the field of illegal coal mining, as well as about the persons who prepare, commit or have committed them;

- targeted operational search for persons who may be witnesses, as well as objects and documents that may be evidence in criminal cases instituted on the facts of illegal coal mining;

- the implementation of materials of operational verification of primary information about crimes in the field of illegal coal mining.

Documentation of crimes in the field of illegal coal mining, in turn, is the following set of actions made by employees of operational units of economic security and anti-corruption carried out as part of the operational case:

- putting forward versions of the circumstances of the crime;

- identification (detection, verification and evaluation) of evidence on the circumstances of the crime, having evidentiary value in the consideration and resolution of a criminal case;

- providing the ability to use evidence for these purposes by fixing in operational documents and other storage media (video, audio, digital).

The main areas of documentation of crimes are:

- identification of persons who have knowledge of crimes in the field of illegal mining of coal, including those related to illegal business and violations of the rules for the protection and use of mineral resources, which may be witnesses of illegal activities (including during the investigation and in court);

- identification of objects and documents that may be evidence in criminal cases, instituted on the facts of crimes in the field of illegal coal mining;

- recording the actions of persons involved in the case of operational records (if a criminal case has already been opened, then those with the status of a suspect or accused of committing a crime) in compliance with the requirements of the Federal Law "On operational search activity" and the Code of Criminal Procedure of the Russian Federation;

- providing the possibility of using and using the obtained documents for the implementation of materials of operational development.

Taking as a basis the approach common for economic crimes [1], we consider the objects of documenting crimes in the field of illegal coal mining. These are:

- the types of crimes in the field of illegal coal mining, the circumstances of their commission (including methods, time, place), ways to hide the traces of a crime, the nature and extent of the damage caused by these crimes;

- the presence and location of documents, items, money obtained by criminal means (including those stolen as a result of committing crimes in the field of illegal mining of coal), as well as documents and items that were instrumental in crime;

- the facts of involvement the instigated persons in the preparation or commission of crimes in the field of illegal coal mining, circumstances aggravating or mitigating their responsibility, information characterizing their personality and features of behavior;

- in the case of group commission of a crime - the form of organization (group of persons by prior conspiracy, organized group, criminal community / organization), its functional structure (obligations of participants, their direct participation in the commission of crimes), prescription of existence, scale of activity (including territorial); 
- the methods of counteraction to law enforcement bodies, including the possible presence of corrupt ties in government and management bodies;

- the reasons and conditions conducive to the commission of crimes in the field of illegal coal mining (as well as at a particular facility);

- other circumstances relevant to the prevention, suppression and disclosure of crimes in the field of illegal coal mining.

\section{Results and discussion}

When detecting crimes in the field of illegal coal mining, the main sources of information on the facts of their commission (preparation) are:

- the statements of individuals and legal entities on the fact of the commission of crimes (the statements must contain information indicating the signs of the above crimes, the approximate amount of damage is determined, documents are attached to the application);

- the results of the operational search activities of the operational units of the internal affairs bodies, as well as information and analytical search (study and system analysis of the materials of criminal cases, cases of operational records);

- the messages of persons providing silent assistance to operational employees of economic security and anti-corruption units;

- the results of the exchange of information with other internal affairs bodies, other law enforcement bodies [2];

- the results of compliance by business entities with licensing, antitrust, tax laws;

- the materials of audit commissions and audits that worked to verify the financial and economic activities of economic entities of the coal industry;

- the data of law enforcement agencies of foreign countries obtained through Interpol channels, including on export coal supplies;

- other sources.

The information received is subject to mandatory verification. In this regard, an important component of identifying crimes in the field of illegal coal mining is the operational verification of primary information, aimed at confirming or refuting it by collecting additional data necessary to make an appropriate decision. The audit allows determining how much the received primary information about the fact of committing a crime in the field of illegal coal mining is confirmed or refuted.

Operational verification of primary information allows the following:

- to establish the presence or absence of objective signs confirming the commission of crimes in the field of illegal coal mining [3];

- to verify the sufficiency of data for sending materials on jurisdiction [4] (in each particular case, the required set of data depends on the facts and persons falling into the field of vision of the operational units);

- to assess whether there is a reason to believe that without a complex operational search measures it is impossible or extremely difficult to expose a person (group of persons) of committing crimes in the field of illegal coal mining.

In the process of identifying and documenting crimes in the field of illegal coal mining, one of the most important areas of activity of the operational units of economic security and anti-corruption is the selection and placement of secret sources of operational information.

The following categories of persons, including on the permanent basis, can act as such sources:

- the employees of organizations and enterprises of the coal industry (including the employees of the security services of these companies) who have information about the commission (alleged commission) of crimes in the field of illegal coal mining [5]; 
- the employees of legal entities (individual entrepreneurs) - owners (tenants) of coal facilities (some have access to management, accounting and other documents; others, for example, the employees of human resources department, have information about those dismissed for various violations of co-employees, about imposing penalties on them);

- the inspectors of territorial divisions of the Federal Agency for Subsoil Use, the Federal Service for Supervision of Natural Resources, the Federal Tax Service, the Federal Antimonopoly Service, and other regulatory bodies may have certain information about committing crimes in the field of illegal mining of coal. The examples are the facts of concealment by other inspectors of revealed violations in the field of subsoil use; the falsification of acts of inspections of subsoil users conducting development of coal deposits; illegal licenses; illegal open pit operations);

- the employees of audit firms and independent auditors [6], analyzing the financial and economic activities of enterprises and organizations of the coal industry, may have information on financial and business operations that are illegal;

- the individuals and legal entities - consumers of products of coal industry enterprises [5] can report: on proposals for the sale of coal at a low price without relevant documents, on the supply of coal that clearly does not correspond to the declared quality, etc.

Unspoken sources involved in the search work most often carry it out focusing on signs indicating the commission of certain crimes. Operational officers need to bring to their secret sources the most complete information about the search for crimes in the field of illegal coal mining.

For example, the following evidences may indicate illegal entrepreneurship in the coal industry:

- the lack of information about the business entity in the Unified State Register of Legal Entities;

- an entry in the register on the liquidation of an economic entity;

- inconsistency of the activities carried out with the profile of the business entity (for example, instead of exploration - coal mining);

- a change in the location of an economic entity (including repeated) without notifying the registration authorities and making the appropriate changes to the constituent documents;

- expiration of the period for which the registration certificate was issued;

- conclusion of contracts under which the total volume of coal supplies exceeds the volume of coal mined at this enterprise;

- the arrival at the railway junctions of a larger number of coal high-sided wagons, compared with usual arrival;

- the lack of control over the conclusion of subcontracts by the general contractor - a geological exploration enterprise - for geophysical research and perforating explosive operations;

- the violation of the terms and volumes of geological exploration, seismic and other works provided for by programs and projects;

- the development of low-power shallow layers of minerals (coal deposits) with their subsequent sale at a low price;

- sending the requests for additional changes to license agreements to the bodies of natural resource regulation by the economic entities of the coal industry - subsoil users (at the same time the actions, as a rule, have already been completed);

- the search and purchase of equipment for coal mining (even obsolete and decommissioned), vehicles for its transportation, etc.

In order to identify and document crimes in the field of illegal coal mining, the operational employees of the economic security and anti-corruption units have to decide what set of operational search measures should be realized within the framework of the operational case. The expediency is determined by analyzing the type and a method of 
committing a crime, information about the persons who committed it. After that, they should carry out organizational, tactical, and material preparation for their implementation [7].

The grounds for a complex of operational search measures to identify and document the above crimes, as a rule, are:

- the presence of a criminal case;

- the availability of information about the signs of a prepared, being committed or having been committed crime in the field of illegal coal mining, as well as about the persons who prepare it, committing or committed, if there is no sufficient data to resolve the issue of initiating a criminal case [8].

According to practitioners, the following investigative measures have the greatest effect in detecting and documenting crimes in the field of illegal coal mining, including those related to illegal business and violations of the rules for the protection and use of mineral resources: inquiry; study of objects and documents [9]; observation; inspection of premises, buildings, structures, terrain and vehicles.

To identify the circumstances of the commission of crimes in the field of illegal coal mining, the formation of the evidence base and criminal prosecution of the perpetrators, in the scientific literature it is recommended to use the following methods of studying documents, certificates, answers to requests and other information:

1. The method of comparative analysis of activity models.

2. The method of comparative analysis of function models.

3. A method of comparing indicators.

4. The method of open verification.

5. The method of economic and legal analysis.

6. Methods for identifying discrepancies in economic indicators.

To increase the efficiency of detecting facts of illegal coal mining, including those related to illegal business and violations of the rules for the protection and use of subsoil, it is recommended that the considered methods should be applied not separately but in combination.

According to the operational staff, the promising operational search measures is the operational implementation, however, there is no practice of using it to identify and solve crimes in the field of illegal coal mining, which is sufficient for analysis and making recommendations. Despite this, the legendary undercover operation of an agent in a criminality, for example, his employment at a coal mining enterprise, which is an object of operational interest, can be very valuable in terms of gathering information and solving tasks of operational search activities.

Test purchase in order to identify and document crimes in the field of illegal coal mining, in our opinion, is a costly and not always effective measure.

Firstly, it is necessary to purchase a sufficiently large volume of products. Secondly, difficulties may arise with the accurate identification of coal as to whether it belongs to a specific producer (although such capabilities are available at the current level of expertise). Thirdly, a coal-selling person almost always has cover documents evidencing the completed purchase and sale transaction (for example, a fictitious supply contract, moreover, concluded with a non-existent organization).

Despite this, it is possible to conduct a test purchase from an economic entity supplying coal with low quality characteristics, which, according to the documents, is considered to a high-quality expensive product.

The operational search measure "controlled delivery" is considered to be one of the effective ways to obtain information about the signs of criminal activity at industrial facilities, however, its significance has not been sufficiently determined with respect to the detection of facts of crimes in the field of illegal coal mining. We believe that it is possible 
to carry out this operational search measure in order to identify the actual operation of the closed open pit (however, such an operational search measure is more likely to be part of an operational experiment or even an operational combination).

Collecting samples for a comparative study involves sampling coal (if necessary, this event is carried out with the participation of a specialist) to determine its group (grade), qualitative characteristics (yield of volatiles, specific heat of combustion, humidity, ash content, sulfur content, mechanical and thermal strength, and etc.).

Other operational search measures may bring certain results, including:

- identification of the person (especially when identifying a criminal group committing theft at the coal industry, to identify the members of the group);

- listening to telephone conversations (for example, you can set the date and time of sending a dump truck with stolen coal from the quarry, as well as the place where it is being sent, names, nicknames or other identification signs of persons transporting stolen coal);

- getting the information from technical communication channels (telex, facsimile, intercom, radio relay data transmission channels, radio communication devices, subscriber telegraphy lines) and receiving computer information [10] (computer networks). It may be any information indicating facts of possible criminal activities (search for excavators, bulldozers, dump trucks (without a lease agreement), drivers of dump trucks and other trucks, coal supply at a price lower than the market);

- operational experiment - to establish the unlawful intentions of persons reasonably suspected of preparing or committing crimes in the field of illegal coal mining.

\section{Conclusion}

1. Activities to identify and document crimes in the field of illegal coal mining is a set of complementary actions to ensure that those responsible are brought to justice.

2. When identifying crimes in the field of illegal coal mining, along with public sources of operational search information, an unofficial source should be used, which may include: employees of organizations and coal industry enterprises; employees of related enterprises and organizations; employees of state supervisory and regulatory bodies; independent auditors; consumers of coal industry products.

3. The detection of crimes in the field of illegal coal mining should be based on the proposed search criteria.

4. In order to identify and document crimes in the field of illegal coal mining, operational employees of the economic security and anti-corruption units should implement the following operational search measures: survey; inquiry; collection of samples for comparative research; study of objects and documents; observation; inspection of premises, buildings, structures, terrain and vehicles; operational implementation; controlled delivery; identification of the person; wiretapping; receiving information from technical communication channels; receiving computer information; operational experiment.

\section{References}

1. Yu. G. Volgin, Operational-search support for the investigation of economic crimes (Kemerovo Institute (branch) of G.V. Plekhanov Russian Economic University, Kemerovo, 2014)

2. V. Shelestukov, V. Erin, G. Pavlov, E3S Web Conf., 41, 02029 (2018)

3. The Criminal Code of the Russian Federation of June 13, 1996 No. 63-FZ (with subsequent amendments and additions) (Collection of the legislation of the Russian Federation, Moscow, 1996) 
4. The Code of Criminal Procedure of the Russian Federation of December 18, 2001 (as amended and supplemented) (Collection of the legislation of the Russian Federation, Moscow, 2001)

5. R. Drapezo, V. Shelestukov, E3S Web Conf., 105, 02016 (2019)

6. P. Gottschalk, L. Gunnesdal, White-Collar Crime in the Shadow Economy (DHG Publishing, Basingstoke, 2018)

7. G. Bammer, Dealing with Uncertainties in Policing Serious Crime (Meadows, Canberra, 2010)

8. On operative-search activity: federal law of August 12, 1995 No. 144-FZ (with subsequent amendments and additions) (Collection of the legislation of the Russian Federation, Moscow, 1996)

9. D. Gray, American Journal of Business Education, 2:1, 117-126 (2008)

10. Transnational Organized Crime. Analyses of a Global Challenge to Democracy (Schönenberg, Berlin, 2013) 